\title{
On the New Mode of Production of Agricultural Modernization
}

\section{- Conception and the Policy Suggestion of Establishing the Countryside Datong's Society}

\author{
Zhang Wenwu, Deng Yong ${ }^{\text {a }}$, Zhang Shihong \\ Institute of Finance, Jilin University of Finance and Economics, 130117 Changchun Jilin, China.
}

\begin{abstract}
Facing the "new four modernizations" requirements, the efficiency of current rural production organization and the supply of agricultural labor is facing a huge challenge. Innovating the pattern of rural production organization has become the only one way to realize agricultural modernization. Based on the analysis of the fatal defects in the current agricultural production organization, we put forward a new mode of modernized agricultural production that can reduce the defects, namely the idea and operation mechanism of Tongpian Society or Datong Society. And also conclude the main breakthrough point of Datong Society and the environment for its full implementation. Finally we put forward some operational countermeasures and suggestions on how to start and develop Datong Society, also mention the problems and things we need in-depth study and need to be done. Hoping our viewpoint can contribute to the development of agricultural modernization.
\end{abstract}

Keywords. Tongpian Society; Datong Society; Agricultural Mechanization

Reform and opening up have made China obtained high growth in the past 30 years and earth-shaking changes in social life. However, in the process of advance to a well-off society all of the nation nowadays, the rural economic and social development have encountered obstacles. Household contract responsibility system seems to have come to an end, but we can not abandon it, because there is no other adapted new mode of production. So the relations of production cannot adapt to the current and future advanced productivity. The people's Commune and brigade system have once valued the public more than the private, which surpass the level of productivity. There are all kinds of the current production organization, but the one which can both really improve the degree of organization of production mechanization production and to adapt to modern agricultural production is still in the exploration.

\section{The traceability of agricultural modernization theory}

\subsection{The transformation of traditional agriculture theory}

\author{
aCorresponding author: DengYong0209@126.com
}

This is an Open Access article distributed under the terms of the Creative Commons Attribution License 2.0, which permits unrestricted use, distribution, and reproduction in any medium, provided the original work is properly cited. 
The transformation of traditional agriculture theory is raised by the famous American economist Theodore w Schulz Te. Schultz's theory of transforming traditional agriculture has great significance to deepening theoretical research of agricultural modernization. The Schultz in his "the transformation of traditional agriculture" in 1964 which pointed out the important position of agriculture in economic development and active function concisely in theory and had proposed a new insights of the nature of the traditional agriculture. He thinks if a developing country wants to promote its economic growth rapidly, it must promote agriculture growth rapidly and stably. However, traditional agriculture simply do not have the ability to grow rapidly and stably, therefore, to enhance the national economic strength, the solution is to turn the traditional agriculture to the modern agriculture fully, namely realizing agricultural modernization.

\subsection{The transformation theory}

To be short, the essence of agricultural modernization is to transform or reform the traditional agriculture to modern agriculture. In eighty or ninety years of the twentieth Century, with the rapid development of China's rural economy, people's understanding of agricultural modernization is gradually deepened. They consider that agricultural modernization is a dynamic, invert and developing process with the development of the science and technology. It should be adapted to the increasingly advanced science and technology by shift production mode, adjust the agricultural structure and the mode of production in order to achieve the level of total factor productivity improvement.

\subsection{System theory}

Expression of present agricultural modernization can be briefly expressed: to improve agricultural productivity through modern technology transform agriculture, and then increase the income of farmers, improve the quality of life of farmers, narrow the difference between workers and peasants and the differences between urban and rural areas, make agriculture into a modern agriculture which has the world advanced level. The view of institutional theory thinks, the agricultural modernization is the reform and innovation of organization system and management method caused by the expansion of the application of science and technology in agriculture. Therefore, the modernization of agriculture is to transform the system of restricting agricultural development, to cooperate fully with the advanced science and technology to improve the efficiency of agricultural production.

\section{Fatal flaws existing in the current agricultural production organization}

Agricultural modernization is the important foundation of national modernization, the power source of sustained and healthy development of the country and the long period of stability, which is the fundamental way to change the backwardness in rural areas and improve the farmers' poor life. In order to realize the agriculture modernization, agricultural productivity must be greatly improved, but at present, China's current agricultural production organization has seriously hindered the effective promotion of agricultural productivity and hampered the pace of agricultural modernization.

\subsection{The potential capacity of present the household contract responsibility system limited by scale}

Our country put the household contract responsibility system into practice since 1978, farmer's independent right of management has been permitted and protected, the labor enthusiasm of farmers has been greatly mobilized, agricultural productivity has got unprecedented development; however, with the accelerated pace of agriculture modernization, the marginal productivity relied on human intensive labor has been close to the vertex, which has lost its edge, and the present household 
contract responsibility system can not form scale operation, the space to be explored has been restricted.

\subsection{Family farms are still hovering in the edge of scale management}

Agricultural development path in developed countries show that: the family farm is one of the important forms of organization to promote the development of agriculture. From the point of view of economics, the essence of family farms is the scale management organization match to the agricultural production which developed to a certain stage, its preconditions is the scale factor of production. As an important element of agricultural production, whether the land can be moderately centralized manage is the basic condition to the development of family farm. However, rural land is extremely fine, fuzzy property rights of rural land and farmers who have serious consciousness, are not willing to sign a long-term land transfer contract, which makes the family farm can not rent the farmland that is party piece, relatively stable, and long-term. A single farm land area is more than a single experience of farmers, but the land is still fragmented and lack of contiguous scale, which make family farms still wander in the edge of scale management.

\subsection{Large farms are still unable to solve the problem of mechanized farming}

Encouraging the development of large farms and promoting the innovation of agricultural production and operation mechanism is the important content of the development of agricultural modernization. However, in order to divide the land in accordance with the fair, calculating by "Mu", "points" and family population quantity, the state average spread the land to every household according to fertile degree, which leads to the farmers' land fragmentation, here a ridge where a block, the land is not concentrated and not suitable for large-scale mechanized farming, which makes essential of a new large farm is just the adjustment of the household contract responsibility system, a land farming mode that one household contract several other households, farming scale of a new large farm is large than experience individual farmers, this mode is still extensive cultivation, extensive management, which is difficult to make farmers scattered land concentrated to use machinery production and still unable to across the gap of mechanized production.

\subsection{Short-sighted behavior of present agricultural cooperatives restricts the increase of the capital organic composition}

Since "Professional Farmers Cooperatives Law of the people's Republic of China" has been formally implemented on July 1, 2007, the professional farmers' cooperatives thrive in all over China, of which the number is rapidly growth and in which the number of farmers are increasing. As of 2013, the number of national real professional farmers cooperatives has been more than 730,000 households; the number of households is about $48,000,000$, accounting for about $17 \%$ of the total number of farmers. But the agricultural scale management did not significantly improve. Because the cooperatives are always engaged in the purchasing of production material, agricultural products sale, storage, transportation, processing services, agricultural technology promotion, information service, etc. The cooperatives rarely set foot in circulation and the scale of production of land. The agency of onion, garlic, potato, peanut, ginger, rice and so on play an important role in organizing farmers to carry out specialized production and be engaged in sales of agricultural products, leading the farmers to participate in market competition, but the land is still scattered and cooperatives only deal with the results of peasant labor in a certain degree, which did not basically change the process and mode of farmer production from the origin. All members are still farming in the most primitive human way of operation of their own piece of land, in which the land is not concentrated to execute mechanization production, so farmers did not improve agricultural productivity. Therefore the organic composition of capital is still at a low level, which is decided by technical composition of capital and reflects the composition of capital value changes. 


\section{The new mode of production of agricultural modernization}

Agricultural production organization of current is only a superficial reform, which is basically restricted in the current situation that the farmer land sporadically decentralized. What's more, land can't be concentrated and produced in the mechanized way, which resulted in improved productivity of agricultural modernization is insufficient and innovation degree is not deep. However, the new realization patterns of agricultural modernization production, such as the same piece of agency and Datong Society, can be an easy way to resolve the fatal flaw of the current agricultural production organization.

\subsection{The conception and operation mechanism of Datong Society in rural areas}

Of livestock breeding, product processing and marketing cooperatives have certain effect on agricultural production and farmers' life, but most of them are partners of temporary joint interest, If the trend of market changes, the source of interest will disappear and the union will be dissolved. That kind of organization has little effect on the rural production relations. In addition, it has little stability and doesn't represent the practical trend. The mode of agricultural production organization is being explored, which can really improve the degree of agricultural production.

\subsubsection{Tongpian Society is the basis of the Datong Society}

Tongpian Society means the specialized cooperatives in the same piece of land. It combines the adjacent lands own by different farmers to a large area of land and set up a joint production cooperatives. Farmers' land ownership is unchanged, but the large piece of land can be used to grow the same plant through mechanize farming, so as to improve the level of agricultural modernization.

\subsubsection{Tongpian Society's expansion}

The mature Tongpian Society, after acquiring the adjacent ones, will be a big deal and can realize the Chinese dream of agricultural modernization. Datong Society is a trend of the land cooperative business model, because of the qualitative change in the aspects of production technology and production tools.

This kind of cooperative is very directional and future, which is the basis of the full implementation of the work of agricultural mechanization. The starting point of Datong Society is the same piece of agency, its operation need every little bit work. First, it starts from a piece of land as an agency and gradually extends to the two pieces of land as an agency, many block adjacent land as an agency, and finally spreads to all parts of the country. This kind of cooperative can make the effect of agricultural mechanization and modernization to be a reality. After the social benefits that business model of the same piece of agency brings are recognized, the same piece of agency will spring up as bamboo shoots after rain. With the situation in which the number of the same piece agency gradually increased, different agency will form the merger trend. From small to big, from weak to strong, it gradually becomes to one chariot one agency, or even one village one agency, eventually forming the Datong society.

\subsubsection{Datong Society is a new mode of land transfer}

Datong Society is on the rural household contract responsibility system for the development and breakthrough. From the household contract responsibility system into the family joint management responsibility system is the transformation from the individual to the entity, this transition is a qualitative leap, farmers becomes new farmers, agriculture transforms modern agriculture. 


\subsection{The main breakthrough point of Datong Society in rural areas}

Datong Society is a breakthrough after the people's Commune, the brigade system and the rural household contract responsibility system, also is an innovation of agricultural production and operation organizations under the new historical conditions.

\subsubsection{Open up a new path of agricultural mechanization}

Tongpian Society can open up a new path that will centralize the land management rights of different farmers to concentrated product, can transform the manual operation mode that one contracts several ridge into a mechanized production that more households in a piece of land, then making the scientific and technological content of agricultural production greatly ascend and changing the farmer's production and operation mode with farmers ownership in the land unchanged.

\subsubsection{Make land gathered to professional farmers, to solve the problem of "who sow the land"}

Because the farmers operate one-third of an acre of distribute $d$ land has been unable to meet the needs of family life, most of the third generation of farmers go out to work, resulting in a large number of loss of rural labor force and emerging the problem of "who sow the land". The implementation of Tongpian Society will choose efficiency man, who can manage the cultivation of land and sales about it, so, individual land will grow up for corporate management, and the use of mechanized production will instead of the shortage of manual labor, Members of Tongpian Society that with no arable farmers can not only the means of production cost. This will not only enhance agricultural productivity, but also can solve the worries and problems of large tracts of uncultivated land.

\subsubsection{Make peasant decentralized operation model upgrading to mass production}

In the face of the household contract responsibility system in rural areas, we love and hate, we love it had started and mobilized the farmers production enthusiasm, promoted the development of Chinese agriculture and the whole national economy. We hate the household contract responsibility system feel uncomfortable when face the higher agricultural science and technology and the larger space that agricultural can be promoted. After Implement the household responsibility system, namely the formation of Tongpian Society, the Situation will complete be changed, rural land scale operation will realize on the basis of no change in the household contract responsibility system, and mechanization and modernization means can be applied to agricultural production, which can makes agricultural transform and upgrade and will greatly promote the development of new agricultural modernization.

\subsubsection{Create a new platform for the promotion and implementation of the policy of supporting agriculture}

There have organizations there have the power, and the wishes expressed through the organization can easy to be attached importance. Tongpian Society make farming entities from the individual entities into a legal entity, this change is not a simple volume, but a qualitative leap, which will make the supporting policy of farmer a new fulcrum, and on behalf of the trend of agricultural modernization, so that the state can be assured and willing to give it greater support on various policy measures about finance, credit science, insurance and technology.

\subsubsection{Promote the rational circulation of rural land in one step}

With the reform of modernization agriculture, the existing agricultural production and operation mode has been more and more can not adapt to the needs of the development of modern and international agriculture. Only accelerating the rural land circulation, focusing on rural land and twenty percent 
people cultivate eighty percent farming land, can agricultural productivity be improved and adapt to the relations of modernization production. The establishment of Datong Society is directly put a piece of land rather than a household as a starting point, which provides just a practical and feasible way for government to press forward to the enemy's capital, and promotes the rational circulation of rural land one step in a direct and fast way.

\subsection{Environmental conditions of Datong Society's full implementation}

\subsubsection{Allow the farmers to understand and accept the Datong Society's operation philosophy}

During the industrialization, urbanization, agricultural modernization and information of the "new four modernizations" period and under the rural basic Household-responsibility system, to keep up with the rhythm of development and seize the opportunities given by the "new four modernizations", rural areas especially the underdeveloped ones have nothing but promote Land Circulation and Concentration at the fastest pace as well as mechanized farming so that they can alter the backward impoverished laborious circumstance. Datong agency business philosophy is to the same piece of service as the foundation, the mechanized production of farmers land down to the household of the scattered land concentrated together in scale, with machinery instead of manual, effectively change the mode of production and mode of operation, improve labor productivity, create mechanization scale benefits for farmers. Therefore, the state should take the necessary measures, in-depth publicity Datong service concept.

\subsubsection{Avoid farmer's worrying about escheat}

Based on the situation of our country's most prominent, the land problem can cause the contradiction. Influenced by traditional ideas, the land in the eyes of the peasants is still the fundamental survival, the lifeline, even if they cannot land and never to yield an inch of ground. In addition, in recent years, accelerating the urbanization process, road and bridge, development zone projects making a large amount of rural land, which was confiscated by non-agricultural construction, make the land-lost farmers increase. The state for the public needs of the land requisition and social conflicts caused by it is often seen, and the concern of farmers for the land is increasingly obvious. Therefore, to avoidance the fear of farmers' land seized on the Datong Society is essential for the implementation of the Datong Society.

\subsubsection{Start with the machinery investment and new support policy for Tongpian Society}

Lack of funds has been a major bottleneck restricting agricultural development in China. Furthermore, throughout the course of agricultural development, the successful development cannot do without the policy support of the government. The government cannot do without large machinery for agricultural development investment and well-bred allowance. Then, to implement the Datong Society, large-scale farming machinery and capital are indispensable. Therefore, increasing financial subsidies during the development of Datong in the implementation of the measures, financial supporting and starting on the same piece of machinery agency devotion and supporting the new policy are necessary.

\section{The countermeasures and suggestions of timely development of new agricultural organization Datong Society}

At present, China's agricultural infrastructure is still weak, the level of agriculture mechanization is low, the quality of workers is low, agricultural income is not high. The establishment of Datong Society can largely solve the situation that traditional agriculture can not adapt to the current development of agricultural modernization. Therefore, it's critical for the smooth development and 
full implementation of Datong Society and for the development of national economy how to develop the fundamental policy.

\subsection{Accelerating the implementation of rural land ownership system}

At present, the urgent problem of implementation of the new policy of land is the land property. Because of the land property rights are relatively vague, farmers are overcautious in use process, and can't safely make land long-term circulation. Once the state announced the rural land ownership, farmers can hold the warrants to safeguard their legitimate rights and interests when they encounter conflicts of interests. Land is the basic means of production, if the land is legally owned, it will solve the peasants' concerns that their contracted land can't be managed or be developed disorderly when they leave the village. Farmer's inner worries have been lifted and it's no longer a problem to make farmers "hand over" their contracted land willingly, thus the establishment of Datong Society becomes natural and the mechanization of agriculture modernization is just around the corner.

\subsection{Determine the management pattern of Tongpian Society and improve its department of mechanism}

Tongpian Society is aimed at promoting agriculture from the laggard mode of production management to modern mechanized production mode, promoting the rural from poverty to the well-off appearance stage of the urbanization, promoting the farmers from the current cultivated hard state to city life modality conversion. However, preparedness ensures success, unpreparedness spells failure. Our country should promote the research for the management mode of Tongpian Society as soon as possible, and make a comparative study on implementation pattern of agricultural modernization, in order to establish priority with Tongpian Society and Datong Society, set up a special operating mechanism of department, formulate relevant regulations and policies and extand the development space of urbanization and agricultural modernization.

\subsection{The government makes efforts to advertise and promote new large-scale agricultural production and management}

Agricultural production and operation model of scale is both the inevitable choice to promote the transition from traditional agriculture to modern agriculture and the route one must take into a comprehensive well-off level. In addition, the scale of agricultural production can improve the efficiency of production in rural areas and urbanization complement each other to promote social progress. The breakthrough point of Datong Society is that it provides the way in which farmer land can be concentrated and implemented to continuous mechanized production. So the government should act as intermediary in the process of Tongpian Society, introduce the policy in all aspects to support and encourage energetically, increase publicity and promotion of new scale of agricultural production and management efforts, make farmer see a change in management pattern of Datong Society, the economies of scale in the future and the development prospects of modern agriculture.

\subsection{The country step up efforts to support and assist}

Countries should develop a series of combined support policies to promote Datong Society, prompt some farmers to transfer out their land for a long time and finally realize concentrated land mechanization production. Combined support measures include: (1) providing financial and credit supports to Tongpian Society, such as giving financial subsidies, tax relief, preferential loan and so on. In other words, government directly provides different scale of the start-up capital and large machinery purchase to the different scale of Tongpian Society; (2) increasing input of agriculture in Tongpian Society, such as supporting with constructions of water conservancy, power, transportation and other agricultural infrastructure. More specifically speaking, free of irrigation and water 
conservancy facilities to more than a certain of Tongpian Society; (3) reducing the management burden of Tongpian Society, such as directly providing science and technology support to Tongpian Society and preventing disorderly apportionments and arbitrary collection of fees for agriculture and farmers.

\subsection{Accelerate the in-depth study on the family business model and the responsibility system}

As early as 1982, the No.1 central document had referred to as far as possible merging and keeping the members' land stable contracted, in order to fully mobilize the enthusiasm of the members and to increase the land utilization rate, but the farmers didn't realize the importance. At present, the scattered rural land has hindering the progress and development of agriculture, and the operation mechanism of fragmented land has inhibiting the production efficiency of large-scale mechanization. Datong Society is continuous production based on Farmers' land right, not only solve the fairness problem of land, but also conducive to large-scale mechanized production. Speeding up the empirical analysis and research of contiguous operation system efficiency, will be conducive to further research and improve the new model, in favor of the production concept of Datong Society becomes reality.

\subsection{Establish training mechanism and creating new model of agricultural jobs}

To promote the development of rhythm of agricultural modernization, it ultimately depends on the new farmers who are well-educated, skillful and good at operating. At present, Many parts of the development of agriculture is faced with "farming without descendants" threat, better quality of the rural labor force basically are engaged in non-agricultural industries and transform into urban inhabitants, remaining agricultural operators generally is not high quality. If the quality of the agricultural operators can not be effectively improved, that it is absolutely impossible to establish an operation mode of modern agricultural development. In such situation, the local government can help Datong Society set ground capable of training mechanism in order to raising farmers' level of mechanization of farming and actual operation, so that the farmers become to agricultural experts who understand management, are good at management, have strong market awareness and ability of management.

\section{Acknowledgement}

Thanks for the Financial Countermeasures Study in Jilin Province Urbanization of Province Social Science Fund Project.

\section{References}

1. Jiang Wenlong, Hu Ligang. The act of breaking title of "stock farm" [N]. farmer daily, February 4, 2013.

2. Han Changchun. The basic problems of Chinese professional farmers cooperatives[D]. master degree thesis of Liaoning Normal University, 2011.

3. Gao Zhijian. the discussion to the modern family farm system — in the direction of land system innovation of rural China's[J]. theory and reform, in 2002 second.

4. Wang Li. The countermeasures and suggestions of rural land circulation problem of agricultural economy [J]. 2010(2): 16-17.

5. Liang Xiaomin. Schultz and "The transformation of traditional agriculture" [J]. agricultural economy, November 27,1985. 